to answer this purpose, even with an ordinary balloon), but we think the management of the balloon may be very well left to Prof. Wise, whose opinion on all practical points of aërostation is probably of more value than that of any other man living. Of all the persons who have devoted themselves professionally to ballooning as a source of income, Prof. Wise is certainly the ablest, and his work on Aëronautics shows him to be possessed of considerable scientific claims. The project could not, thercfore, be in better hands ; and considering the originality and boldness displayed by Prof. Wise in several of his very numerous ascents; there is every reason to believe that nothing will be left undone to bring it to a successful issue. In all the technical matters relating to the balloon, therefore, Prof. Wise may be well trusted to take the best course; and with regard to the meteorological questions involved by consulting not only American meteorologists but also Mir. Glaisher and other gentlemen who have studied the question of the winds in relation to aërostation, it is clear that he intends to leave no stone unturned to obtain the best information attainable, and, at all events, merit success.

\section{MAYNE'S SIDEREAL DIAL}

THIS instrument consists of two moveable circles, which may be made of brass or pasteboard, placed in a common watch-case. The lower and outer one shows the hours doubled up to XXIV., and divided into quarters. The upper one, which is also inner, shows the sixty minutes, 5, 10, \&c. This circle is a narrow one, and works on the plain inmost rim of the lower one, so as to admit of the hours being seen outside the minutes.

Each circle being set to show at the top of the case, where the XII. of the watch comes, the "Sidereal Time at Mean Noon" (given in the Nautical Almanack for each day in the year), the watch is placed in the case, and will continue to show the sidereal time corresponding to mean time approximately for six hours, after which interval the minute circle should $\mathrm{b} z$ put on one minute to ensure greater exactness.

This will be found a near enough approximation for the amateur observer, using an equatorial instrument, and this simple method will be found to save an infinite amount of trouble in finding objects wuhose R.A. is re.

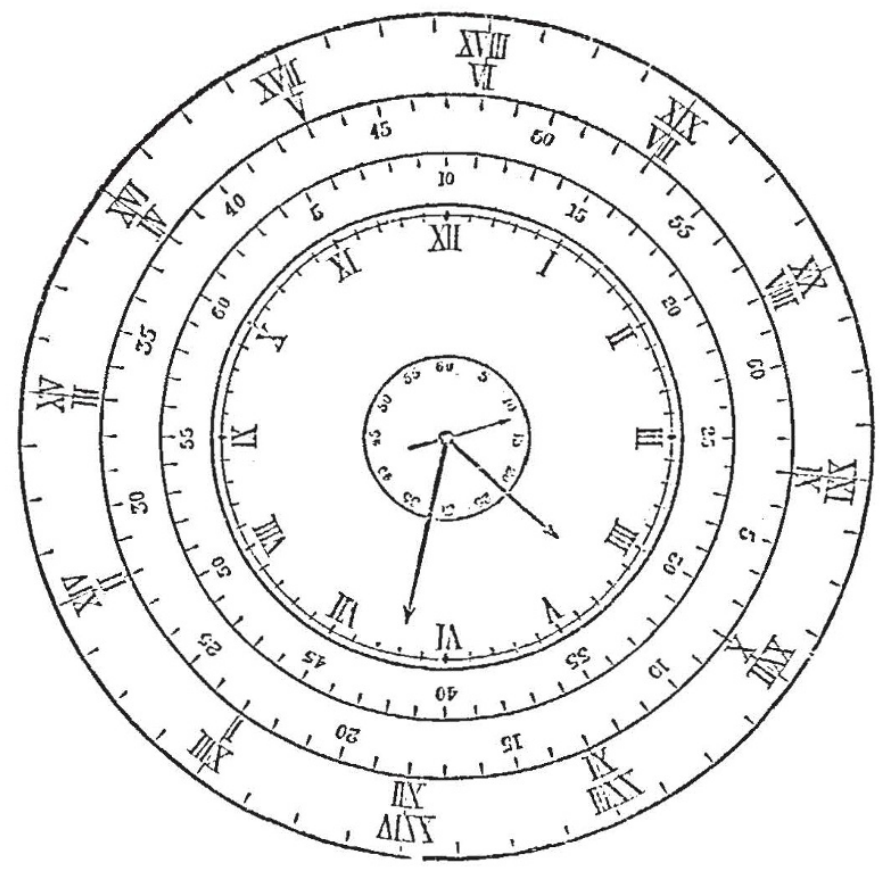

corded in a calalogue, to those who, like the inventor, are unprovided with a sidereal clock.

Mr. Norman Lockyer has suggested as an improvement, the usc of a watch with the seconds' hand in the centre; this would necessitate a third, and still inner circle for the sixty seconds, by which, indeed, subject to an hourly correction of, say ten seconds being tut on, the dial would be rendered accurate enough for rough transit observations; and this circle and seconds hand have been added to the original design in the woodcut, where the dial is set to $\mathrm{V}$. (3) $\left.43_{5}^{3}\right) 47^{\circ} 10$, the Sidereal Time at Mean Noon for the 18 th June, 1873, the hands of the watch representing IV. (1) $32^{*} 12$, which gives the corresponding Sidereal Time X. I9'22 (or applying the last-named correction, say 45 seconds for $4 \frac{1}{2}$ hours), $\mathrm{X}$. $20 \%$.

It is as well perhaps, though scarcely needful, to add (for no one would be likely to make a mistake of 12 hours) that as the dial in the Example also reads XVII. ( $\left.\begin{array}{l}3 \\ 4\end{array}\right) 47^{\circ}$ Io, and as the mean time by the watch may be A.M. or P.M., the observer should bear in mind which half of the 24 hours, both astronomical and mean, he is working in.

The third or seconts circle is not indispensable, as the seconds hand, even in the ordinary position, can be made to fulfil its object, by setting. it at noon to the Sidereal Second on the meridian; thus, in the Example, it would be set to ro, instead of to Zero, when the dial is set at noon, the correction for the equivalent of the lapsed in. terval being applied subsequently as required. But this involves altering the watch, which is objectionable; the use of the third, or seconts circle, is therefore recommended, for although the seconds' hand, as placed in most watches, would not actually point to the Sidereal second, it is easy to refer the position of the mean second to the corresponding part of the watch's face, where the third circle can be read off at once.

\section{Ashton Mayne, Captain,} Bombay Staff Corps, Care of Messrs. Henry S. King \& Co., 65 , Cornhill, London, E.C. 